\title{
Allergic Contact Dermatitis from Diethyl Sebacate in a Topical Antimycotic Medicament
}

\author{
Ayaka Hirao ${ }^{1}$, Naoki Oiso ${ }^{1,2 *}$, Megumi Hama ${ }^{1}$, Noriko Higashimori ${ }^{1}$, Yoichi Tatsumi ${ }^{2,3}$, \\ Akira Kawada ${ }^{1}$ \\ ${ }^{1}$ Departments of Dermatology, Kinki University Faculty of Medicine, Osaka, Japan; ${ }^{2}$ Departments of Patient Safety and Management, \\ Kinki University Faculty of Medicine, Osaka, Japan; ${ }^{3}$ Departments of Hematology, Kinki University Faculty of Medicine, Osaka, \\ Japan. \\ Email: *naoiso@med.kindai.ac.jp
}

Received June $24^{\text {th }}, 2012$; revised July $29^{\text {th }}, 2012$; accepted August $12^{\text {th }}, 2012$

\begin{abstract}
Diethyl sebacate is used in topical medicaments in United States and Japan. We described a case of allergic contact dermatitis from diethyl sebacate in a topical antimycotic medicament. Allergic reaction to diethyl sebacate is likely more common because our group has found three of eight sensitized cases. We believe that an investigation regarding the sensitized frequency to diethyl sebacate would conduct to improve the safety of products in United States and Japan.
\end{abstract}

Keywords: Allergic Contact Dermatitis; Patch Test; Allergen; Diethyl Sebacate; Safety Evaluation

\section{Introduction}

Diethyl sebacate facilitates penetration of effective ingredients [1]. It is used in United States and Japan in some topical medicaments such as antimycotic, corticosteroidal, non-steroidal anti-inflammatory ointments, creams and lotions [1]. The substance may provoke allergic contact dermatitis [1-6].

Topical medicaments usually consist of an effective drug, additives and a solvent, all of which may induce allergic reaction. Each ingredient in the same products may cause allergic and photoallergic contact dermatitis [7-11]. Thus, patch testing is essential for deciding the strategy to prevent the recurrence of allergic and photoallergic contact dermatitis in each patient as well as to design the reduction of sufferers in the social society.

\section{Case Report}

A 39-year-old Japanese man visited us with pruritic erythematous macules and vesicles on the dorsa of the left foot and toes, where he had applied a topical antimycotic solution containing liranaftate $2 \%$, a cream containing liranaftate $2 \%$, a cream containing amorolfine hydrochloride $0.5 \%$, and a cream containing ketoconazole $2 \%$ (Figure 1). A 2-day closed patch test was done with these topical medicaments. A positive reaction was only observed to the solution containing liranaftate $2 \%$ at $\mathrm{D} 2(+)$ and D4(+). A second patch test was done using each of

"Corresponding author. the solution's ingredients, which were provided by the manufacturer. This second test produced a positive reaction to diethyl sebacate $5 \%$ pet. at $\mathrm{D} 2(+)$ and $\mathrm{D} 4(+)$ (Figure 2). All other ingredients were negative. Diethyl sebacate is not used in the other used topical medicaments or in the cream containing liranaftate $2 \%$.

\section{Discussion}

Seven of eight cases including this presentation were sensitized to diethyl sebacate as a result of applying topical antifungal medicaments [2-6]. Three sensitized cases were found by our group [1,3]. The interview forms for topical antifungal medicaments usually report

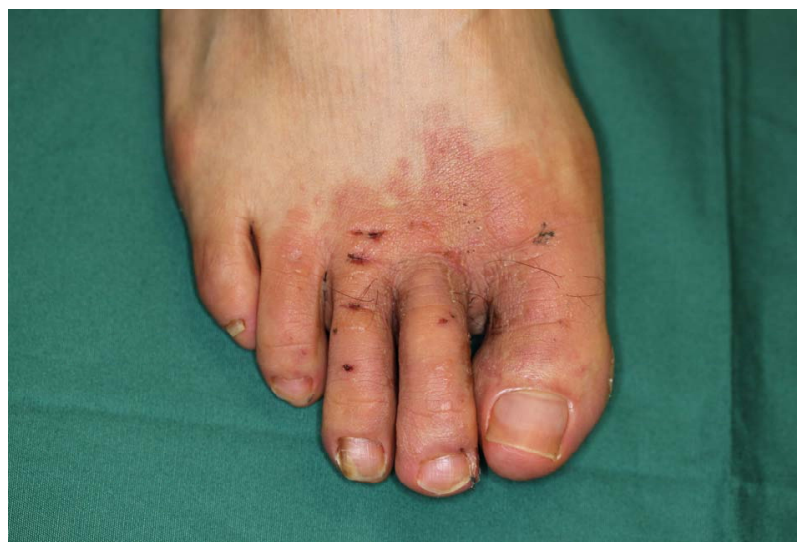

Figure 1. Clinical appearance of pruritic erythematous macules and vesicles on the dorsa of the left foot and toes. 


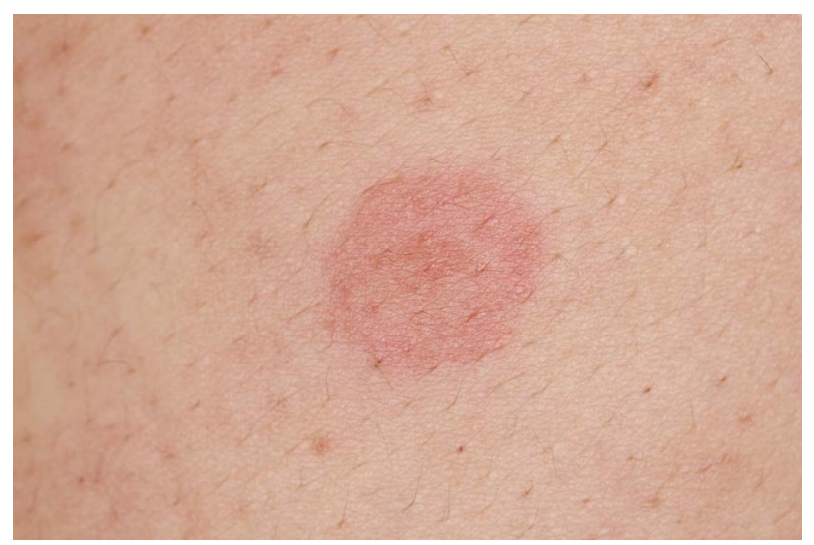

Figure 2. Patch testing produced a positive reaction to diethyl sebacate $5 \%$ pet. at $\mathrm{D} 4(+)$.

that approximately $1 \%$ to $2 \%$ of users experience allergic contact dermatitis to the product. Allergic reaction to diethyl sebacate is likely more common.

Allergic contact dermatitis from topical medicaments has been reported in cases caused by 1) effective drugs such as clotrimazole [12] and luliconazole [13]; 2) additives including parabens [14], 1,3-butylene glycol [15], enoxolone [16], diisopropanolamine [9,10], and menthol [7]; and 3) solvents like lanoline alcohol [17]. The trend of the sensitized frequencies has been studied in the well known allergens such as parabens $[18,19]$ and lanolin alcohol $[19,20]$. However, little is known in diethyl sebacate.

Our current case indicates the need to investigate the sensitization frequency to diethyl sebacate in United States and Japan for safety for patients.

\section{REFERENCES}

[1] T. Narita, N. Oiso, T. Ota, S. Kawara and A. Kawada, "Allergic Contact Dermatitis Due to Diethyl Sebacate in a Hand Cream," Contact Dermatitis, Vol. 55, No. 2, 2006, p. 117. doi:10.1111/j.0105-1873.2006.0866d.x

[2] K. W. Schneider, "Contact Dermatitis Due to Diethyl Sebacate," Contact Dermatitis, Vol. 6, No. 7, 1980, pp. 506507. doi:10.1111/j.1600-0536.1980.tb05586.x

[3] M. Kimura and M. A. Kawada, "Contact Dermatitis Due to Diethyl Sebacate," Contact Dermatitis, Vol. 40, No. 1, 1999, pp. 48-49.

doi:10.1111/j.1600-0536.1999.tb05978.x

[4] E. Sasaki, M. Hata, J. Aramaki and M. Honda, "Allergic Contact Dermatitis Due to Diethyl Sebacate," Contact Dermatitis, Vol. 36, No. 3, 1997, p. 172. doi:10.1111/j.1600-0536.1997.tb00412.x

[5] M. Tanaka, S. Kobayashi, T. Murata, A. Tanikawa and T. Nishikawa, "Allergic Contact Dermatitis from Diethyl Sebacate in Lanoconazole Cream," Contact Dermatitis, Vol. 43, No. 4, 2000, pp. 233-234.

[6] F. Soga, N. Katoh and S. Kishimoto, "Contact Dermatitis Due to Lanoconazole, Cetyl Alcohol and Diethyl Seba- cate in Lanoconazole Cream," Contact Dermatitis, Vol. 50, No. 1, 2004, pp. 49-50. doi:10.1111/j.0105-1873.2004.00271j.x

[7] T. Ota, N. Oiso, Y. Iba, T. Narita, S. Kawara and A. Kawada, "Concomitant Development of Photoallergic Contact Dermatitis from Ketoprofen and Allergic Contact Dermatitis from Menthol and Rosin (Colophony) in a Compress," Contact Dermatitis, Vol. 56, No. 1, 2007, pp. 47-48. doi:10.1111/j.1600-0536.2007.00940.x

[8] T. Rindo, N. Oiso, Y. Yamadori, H. Hirao, S. Kawara and A. Kawada, "Photoallergic Contact Dermatitis Due to Ketoprofen and Hydrogenated Rosin Glycerol Ester," Case Reports in Dermatology, Vol. 2, No. 1, 2010, pp. 36-39. doi:10.1159/000305052

[9] N. Oiso, K. Fukai and M. Ishii, "Triple Allergic Contact Sensitivities Due to Ferbinac, Crotamiton and Diisopropanolamine," Contact Dermatitis, Vol. 49, No. 5, 2003, pp. 261-263. doi:10.1111/j.0105-1873.2003.0225e.x

[10] T. Rind, N. Oiso, A. Hirao and A. Kawada, "Allergic Contact Dermatitis with Diffuse Erythematous Reaction from Diisopropanolamine in a Compress," Case Reports in Dermatology, Vol. 2, No. 1, 2010, pp. 50-54. doi: $10.1159 / 000313430$

[11] N. Oiso and A. Kawada, "Review of Allergic and Photoallergic Contact Dermatitis from an Ingredient in a Medicament Vehicle Consisting of a Compress, Poultice, Plaster, and Tape," Journal of Allergy, Vol. 2011, 2011, Article ID: 169432 . doi:10.1155/2011/169432

[12] S. Erdmann, M. Hertl and H. F. Merk, "Contact Dermatitis from Clotrimazole with Positive Patch-Test Reactions Also to Croconazole and Itraconazole," Contact Dermatitis, Vol. 40, No. 1, 1999, pp. 47-48. doi:10.1111/j.1600-0536.1999.tb05977.x

[13] M. Shono, "Allergic Contact Dermatitis from Luliconazole," Contact Dermatitis, Vol. 56, No. 5, 2007, pp. 296297. doi:10.1111/j.1600-0536.2006.01023.x

[14] N. Oiso, F. Fukai and M. Ishii, "Allergic Contact Dermatitis Caused by Parabens in a Compress," Contact Dermatitis, Vol. 50, No. 5, 2004, p. 317. doi:10.1111/j.0105-1873.2004.00341d.x

[15] N. Oiso, K. Fukai and M. Ishii, "Allergic Contact Dermatitis Due to 1,3-Butylene Glycol in Medicaments," Contact Dermatitis, Vol. 51, No. 1, 2004, pp. 40-41. doi:10.1111/j.0105-1873.2004.0378h.x

[16] N. Oiso, T. Ota, E. Yoshinaga, H. Endo, S. Kawara and A. Kawada, "Allergic Contact Dermatitis Mimicking Atopic Dermatitis Due to Enoxolone in a Topical Medicament," Contact Dermatitis, Vol. 54, No. 6, 2006, p. 351. doi:10.1111/j.0105-1873.2006.0645i.x

[17] J. C. Nguyen, G. Chesnut, W. D. James and M. Saruk, "Allergic Contact Dermatitis Caused by Lanolin (Wool) Alcohol Contained in an Emollient in Three Postsurgical Patients," Journal of the American Academy of Dermatology, Vol. 62, No. 6, pp. 1064-1065. doi:10.1016/j.jaad.2009.10.020

[18] S. Cheng, M. Cao, Y. Zhang, S. Peng, J. Dong, D. Zhang, Z. Jiang and Y. He, "Time Trends of Contact Allergy to a Modified European Baseline Series in Beijing between 2001 and 2006," Contact Dermatitis, Vol. 65, No. 1, 2011, 
pp. 22-27. doi:10.1111/j.1600-0536.2011.01897.x

[19] E. Dastychová, M. Necas and V. Vasku, "Contact Hypersensitivity to Selected Excipients of Dermatological Topical Preparations and Cosmetics in Patients with Chronic Eczema," Acta Dermatovenerol Alp Panonica Adriat, Vol. 17, No. 2, 2008, pp. 61-68.

[20] E. M. Warshaw, D. D. Nelsen, H. I. Maibach, J. G. Marks,
K. A. Zug, J. S. Taylor, R. L. Rietschel, J. F. Fowler, C. G. Mathias, M. D. Pratt, D. Sasseville, F. J. Storrs, D. V. Belsito and V. A. De Leo, "Positive Patch Test Reactions to Lanolin: Cross-Sectional Data from the North American Contact Dermatitis Group, 1994 to 2006," Dermatitis, Vol. 20, No. 2, 2009, pp. 79-88. 